\title{
Research on the Structure and Characteristics of the Overall Social Network of Professional Athletes
}

\author{
Shuqin Cui $\mathbb{D}^{1},{ }^{1}$ Mingyou Gao ${ }^{(D)},{ }^{2}$ Yang Xun ${ }^{(D)},{ }^{3}$ Sai-Fu Fung $\left(\mathbb{D},{ }^{4}\right.$ Yujiao Tan $\left(\mathbb{D},{ }^{5}\right.$ \\ Yu Zhang $\mathbb{D}^{5},{ }^{5}$ Chenghao Wang $\mathbb{D}^{5},{ }^{5}$ Huanqing Wang $\mathbb{D}^{1},{ }^{1}$ and You Xiong $\mathbb{D}^{1}$ \\ ${ }^{1}$ Sport College, Xi'an University of Architecture and Technology, Xi'an 710311, China \\ ${ }^{2}$ Yulin University, Yulin 719000, China \\ ${ }^{3}$ School of Economics and Finance, Xi'an Jiaotong University, Xi'an 710049, China \\ ${ }^{4}$ City University of Hong Kong, Hong Kong \\ ${ }^{5}$ Xi'an Physical Education University, Xi'an 710065, China \\ Correspondence should be addressed to Mingyou Gao; 350441003@qq.com
}

Received 26 June 2020; Revised 31 August 2020; Accepted 27 April 2021; Published 8 May 2021

Academic Editor: Fei Xiong

Copyright ( $\odot 2021$ Shuqin Cui et al. This is an open access article distributed under the Creative Commons Attribution License, which permits unrestricted use, distribution, and reproduction in any medium, provided the original work is properly cited.

\begin{abstract}
This study chooses Chinese athletes as the research object and constructs the overall network of its social support network and discussion network. From the micro-, meso-, and macrolevels of the social network structure, the structure and characteristics of the athlete's overall social network are analyzed. Through research, we found that there is embeddedness, that is, the relevance, between society support networks, between society discussion networks, and between society support networks and society discussion networks. At the same time, in the athletes' social support network and social discussion network, some athletes have no contact with other players; they have no "power" in the group as well, so it is difficult to obtain network resources. We also found that there are small-world characteristics in the social network of Chinese professional athletes. The above findings will provide a deeper understanding of the peculiarities of athlete groups and have certain practical significance for improving athletes' daily training and life management conditions.
\end{abstract}

\section{Research Background}

For a long time, the cultivation of professional athletes in our country has mainly adopted the government-led athlete training system; that is, the government funded the establishment of sports schools at all levels and administratively intervened. Athletes competed on behalf of the local governments, and those with outstanding results were sent to provincial professional sports teams and then selected into the national team, which is a three-level training system for athletes under the guidance of the typical planned economy; that is, the national team is the first level, the provincial professional team is the second level, and the city and county amateur sports schools are the third level. This is also the difference between the current training system for professional athletes in my country and the training system for athletes based on club training abroad. When professional athletes in our country in relatively independent training, learning, and living environment, they may have problems in terms of employment, cultural level, professional skills, and psychology [1-3]. Social network refers to the relatively stable relationship system formed by the interaction between individual members of the society, focusing on the interaction and connection between people [4-6]. Social interaction is carried out under definite circumstances. People have different ways of interaction in different situations. In different situations and different types of relationships, people's interaction process will also be different. Then, through the study of athletes' social network structure, it will further reveal the social interaction between athletes, which will have a long-term important role in improving athletes' athletic performance, mental health, and career planning. Social network is not only a research method but also a research object in itself. Social network research is mainly 
carried out in two directions: Whole Network and EgoCentric Network/Personal Network [7-9].

Social network theory emphasizes the importance of "relationship" and the interaction between individuals, breaking the conventional "attribute" research. While showing a strong empirical analysis ability, a bridge has been separately established between individual rational choice and social constraints and between microbehavior and macrophenomena. Social network theory has been widely used in many fields of social science research, such as management and sociology [10-13]. In a sense, the social performance of professional athlete groups is the effect of social networks and their sports. Social network analysis can be said to be a research paradigm, which is easier to enter the special lives of professional athletes [14].

The whole network can reveal the structure of the social network very well, so when studying the social network structure of professional athletes in our country, we use the method of the whole network structure to analyze the social network structure of professional athletes in our country.

\section{Theoretical Analysis of the Characteristic Variables of the Whole Social Network of Professional Athletes}

The whole network focuses on the relationships within the group and analyzes the interpersonal interaction and exchange patterns with the network concepts of compactness, distance, and centrality. For the whole network research of social networks, the purpose is to reveal the structural features of the social network. The whole social network structure can be divided into three levels: micro, meso, and macro [15].

2.1. Microstructure. Centrality is the main feature of the social network microstructure and one of the focuses of social network analysis. Centrality reflects the size of individual's power in the network [5]. Centrality is usually measured by three indicators: degree centrality, closeness centrality, and betweenness centrality [16]. If the individuality has more degree centrality, it indicates that the individual is in a central position and thus has greater power. If the individuality has more closeness centrality, it means that he is very close to other points, so he does not depend on others. The betweenness centrality shows the extent to which an individual can connect or control others. Through the analysis of the microstructure, we can see the core leaders in the athletes group and whether there are isolated points in the group, so as to grasp the whole network of athletes.

2.2. Mesostructure. For human society, individuals combine into small groups through interpersonal interactions and use social networks to obtain various social resources embedded in them [17]. Relevant research shows that there is a small group phenomenon in the athlete group, but the research is mainly qualitative analysis and lacks quantitative research. This paper will analyze the structure of the small group of athletes from the modular index of the community structure $[18,19]$.

2.2.1. Newman Community Structure Definition. Let the network node set $\mathbf{V}_{p}, \mathbf{V}_{q}$ be the true subset of $\mathbf{V}$; that is, $\mathbf{V}_{p} \neq \varnothing, \mathbf{V}_{q} \neq \varnothing$ and $\mathbf{V}_{p} \subset \mathbf{V}, \mathbf{V}_{q} \subset \mathbf{V}$; if $\mathbf{V}_{p} \cap \mathbf{V}_{q}=\varnothing$, then $\mathbf{A}_{p q}=\left\{a_{i j}\right\}, i \in V_{p}, j \in V_{q}$, and $\mathbf{A}_{p q} \subset \mathbf{A}$. Note that $\|\mathbf{A}\|=$ $(1 / 2) \sum_{i} \sum_{j} a_{i j}$ is the number of node relationships. So when $p \neq q,\left\|\mathbf{A}_{p q}\right\|=\sum_{i \in \mathbf{V}_{p}} \sum_{j \in \mathbf{V}_{q}} a_{i j}, a_{i j} \in \mathbf{A}$ is the number of relationships between subset $\mathbf{V}_{p}$ and subset $\mathbf{V}_{q}$; when $p=q$, $\left\|\mathbf{A}_{p p}\right\|=(1 / 2) \sum_{i \in \mathbf{V}_{p}} \sum_{j \in \mathbf{V}_{p}} a_{i j}, a_{i j} \in \mathbf{A}$ is the number of internal relationships in the subset. Actually, Newman's modularity index that measures the effectiveness and rationality of community structure division is

$$
Q=\sum_{p=1}^{m}\left[e_{p p}-\left(\sum_{q=1}^{m} e_{p q}\right)^{2}\right] \text {. }
$$

2.3. Macrostructure. The network indicators of all actors in a group reflect the macrostructure of the network, that is, the whole structure. Such network indicators mainly include density, out-degree centralization, in-degree centralization, and betweenness centralization [20,21]. Density is the most commonly used measure in network analysis. It shows the difference of edges' distributions between the measured graph and the completed graph. Degree centralization is different from centrality. Centrality is to describe the "power" of a single actor from the perspective of an individual, while centralization reveals the whole centrality of the network graph. In fact, the centralization measures the centrality difference of all actors. Out-degree centralization, in-degree centralization, and betweenness centralization measure in the network the difference in all actors' ability to expand relationships, reputation, and the ability to act as a bridge or control resource between any other two actors $[22,23]$.

Centralization measures the whole centrality of the network. It is a kind of "variance" of the centrality of each individual in the overall network. There are out-degree centralization, in-degree centralization, and betweenness centralization. The calculation formula of the centralization $[18,24]$ is

$$
C=\frac{\sum_{i=1}^{n}\left(C_{\max }-C_{i}\right)}{\max \left[\sum_{i=1}^{n}\left(C_{\max }-C_{i}\right)\right]} .
$$

The members of the professional athlete's social support network and social discussion network overlap to a great extent and whether the two types of networks are embedded in each other can be analyzed through traditional social networks. After as a whole revealing the embeddability of the two types of networks, the macrostructure of the social support network and the social discussion network is analyzed separately through indicators such as network density. Complex network analysis is mainly to reveal the features of the small world. The small-world features (macrostructure) are based on the mesostructure and 
calculate two feature indicators, the clustering coefficient and the path length, and reveal the features of the relationship transmission of the athlete's social network by comparing with the index of the random network of the same scale and the same relationship [24-27].

The clustering coefficient reflects the degree of aggregation of network nodes, referring to the probability that two other nodes connected to the same node are also connected $[28,29]$. The greater the clustering coefficient, the more stable the relationship between network members. The calculation formula of the average clustering coefficient is

$$
C=\frac{1}{n} \sum_{i=1}^{n} \sum_{j, l \in \Gamma_{i}} \frac{X(j, l)}{\# \Gamma_{i}\left(\# \Gamma_{i}-1\right) / 2} .
$$

Average path length refers to how many steps one node in the overall network averages to reach another node $[30,31]$. If we define the shortest distance between node $i$ and node $j$ as $d(i, j)$, the average path length is calculated as

$$
L=\frac{1}{n} \sum_{i=1}^{n} \sum_{j \neq i} \frac{d(i, j)}{n-1} .
$$

\section{Research Design}

3.1. Data Sources and Research Methods. The data used by research come from a sampling survey of professional athletes in Zhangba Training Base affiliated to Shaanxi Provincial Sports Bureau. This training base uses a threelevel training system for athletes under the guidance of a typical planned economy. It is not only a large training base in Shaanxi Province but also a relatively large and concentrated training items in the country. Zhangba Training Base is located in relatively independent training, learning, and living environment, including Shaanxi Gymnastics Management Center (competitive team and competitive gymnastics team), Shaanxi Martial Arts Center (Martial arts Taolu and Sanda team), Shaanxi Heavy Competitive Center (wrestling, weightlifting, and judo team), Shaanxi football Center (men's and women's football team), and Shaanxi Swimming Center (swimming team and diving team). Nearly 1000 professional athletes are training here. Therefore, it has certain representation to select Zhangba Training Base of Shaanxi Province as the investigation place of Chinese professional athletes and to take samples from the athletes in the base [32].

We sent out 144 questionnaires, all of which recover accurately and effectively. Among 144 professional athletes, the proportion of male athletes is more, accounting for $68.8 \%$. The athletes were relatively young, the maximum age was 30 years old, and the minimum age was 12 years old, with an average age of 18.8. In the geographical area, we were mainly divided into outside Shaanxi Province, Xi'an city, and other cities in Shaanxi Province, of which the proportion of people outside Shaanxi Province was the largest, accounting for about $50 \%$. In sports programs, we chose five sports centers to accommodate athletes engaged in different types of training as much as possible, so that the survey data are more objective and reasonable. In terms of education, most of them have received high school education or above, and nearly one-third of them have received college or undergraduate education, which shows that the athletes' education level is relatively high. At the same time, we also investigated the reasons why they chose to be an athlete at the beginning. For most of the athletes, their reasons are "their own interests" and "suggestions of family and friends." The overall network data are divided into two aspects. One is the overall support network (A-E), which includes A-actual support, B-emotional support, C-society communication support, D-employment support, and E-achievement support. Second is the whole discussion network (F-H), F-income discussion network, G-professional discussion network, and $\mathrm{H}$-marriage discussion network. Investigation process: first, encode all the members in the network to form the overall network boundary, then investigate each individual in the network to determine the network members who have communication with themselves in the network boundary, and ask the respondents to answer whether the members of the network give their actual support, emotional support, and society intercourse support [33].

3.2. The Construction of the Overall Network Topology Diagrams of Professional Athletes. Based on the principles of complex network analysis and system engineering, we have constructed 8 whole social networks of professional athletes from two aspects: overall support network and whole discussion network. Among them, A-E are the overall support networks, which include A-actual support, B-emotional support, C-society communication support, D-employment support, and E-achievement support. F-H are whole discussion networks, which includes F-income discussion network, G-professional discussion network, and H-marriage discussion network. The topology diagrams built with UCINET are shown in Figure 1.

\section{Analysis of the Overall Social Network Characteristics of Professional Athletes}

\subsection{Microstructure Analysis}

4.1.1. Degree Centrality. Table 1 provides the degree centrality of the social support network and social discussion network of professional athletes. From the perspective of minimum value, it can be seen that each professional athlete's network has isolated points and they do not have support behavior with anyone. From the view of maximum value, the out-degree is generally greater than the in-degree, indicating that the professional athletes are more likely to ask for help than to accept it passively. Among the five kinds of support networks, the mean value of degree centrality of actual support and society intercourse support is larger which means that athletes support each other more in daily life and society intercourse, while the mean value of degree centrality of employment support network is the smallest, then, in turn, emotional support and achievement support. 


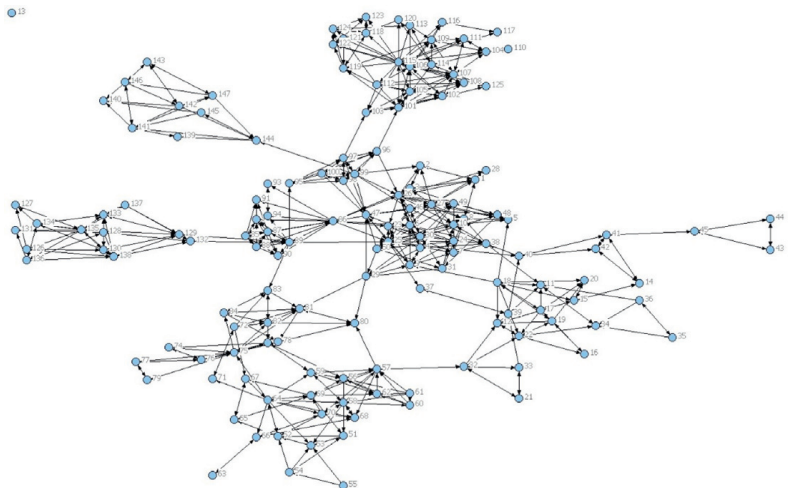

(a)

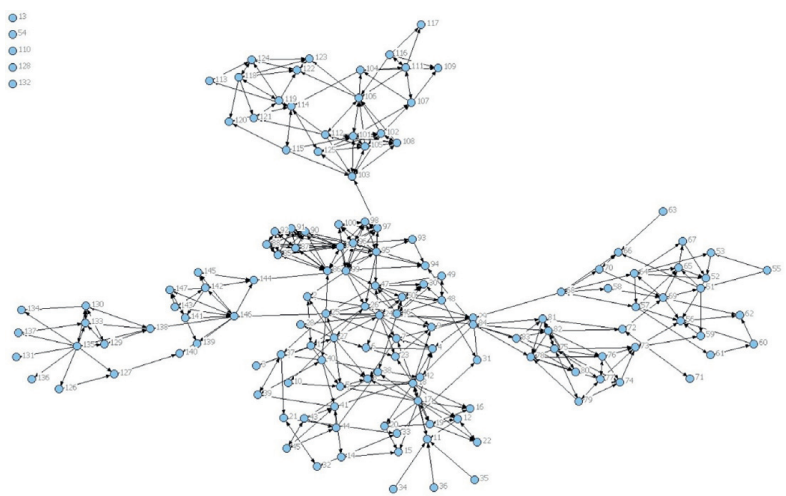

(c)

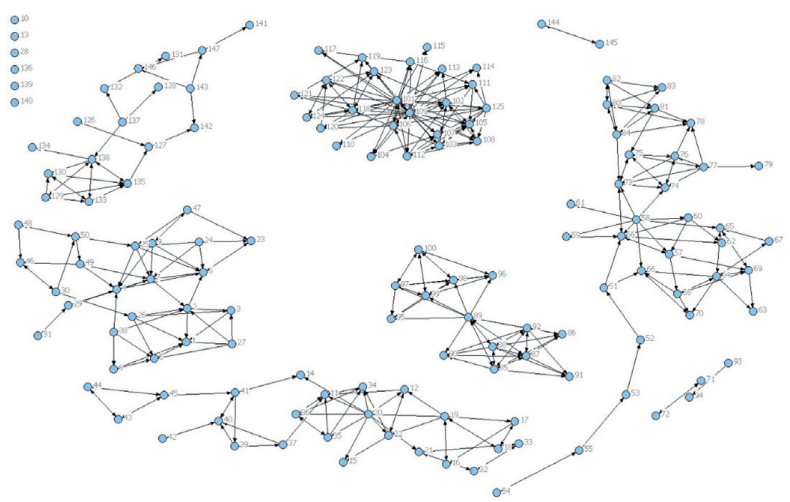

(e)

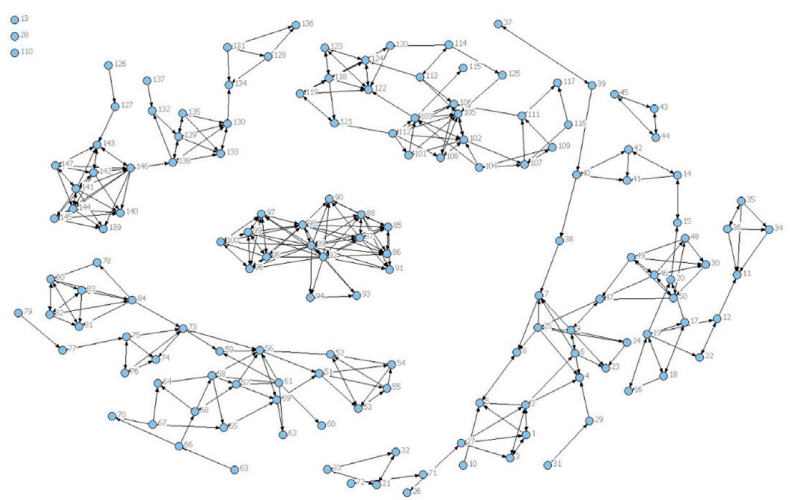

(g)

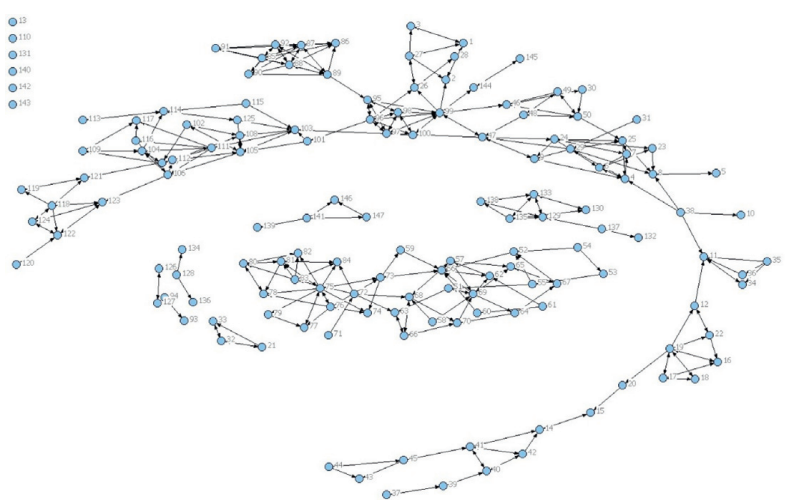

(b)

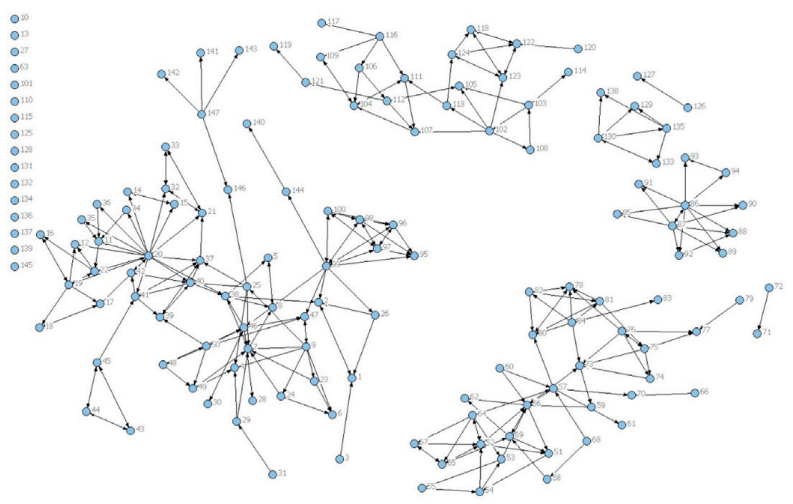

(d)

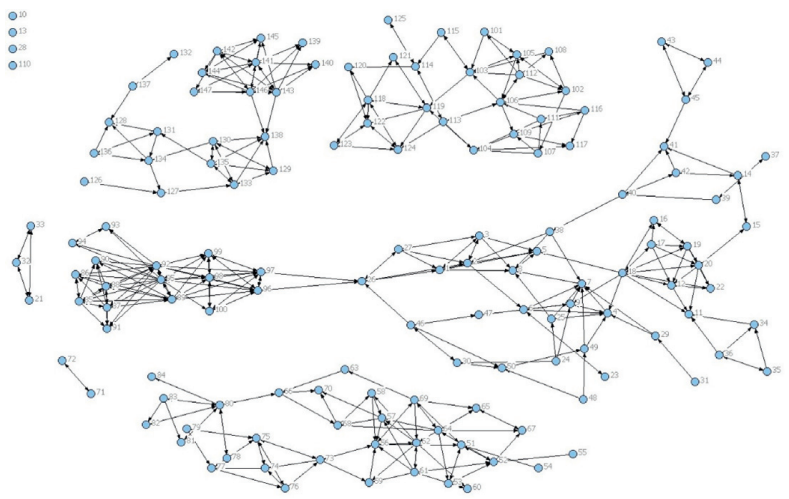

(f)

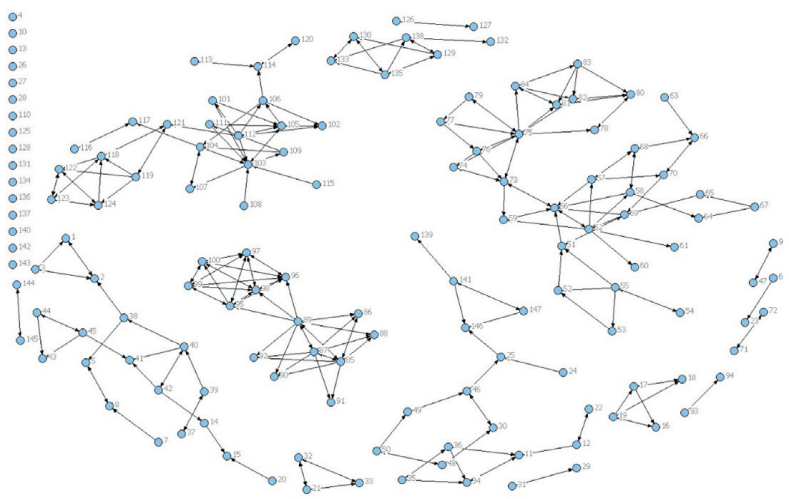

(h)

FIgURE 1: Topology diagrams of the overall social network of professional athletes. 
TABLE 1: Social network degree centrality of professional athletes.

\begin{tabular}{|c|c|c|c|c|c|c|c|c|c|}
\hline & & \multicolumn{4}{|c|}{ Out-degree } & \multicolumn{4}{|c|}{ In-degree } \\
\hline & & Mean & Standard deviation & Minimum value & Maximum value & Mean & Standard deviation & Minimum value & Maximum value \\
\hline \multirow{2}{*}{ A } & $\mathrm{C}_{\mathrm{AD}}$ & 3.471 & 3.349 & 0 & 24 & 3.471 & 2.268 & 0 & 10 \\
\hline & $\mathrm{C}_{\mathrm{RD}}$ & 2.054 & 1.981 & 0 & 14.201 & 2.054 & 1.342 & 0 & 5.917 \\
\hline \multirow{2}{*}{ B } & $\mathrm{C}_{\mathrm{AD}}$ & 2.012 & 1.919 & 0 & 10 & 2.012 & 1.659 & 0 & 6 \\
\hline & $\mathrm{C}_{\mathrm{RD}}$ & 1.19 & 1.135 & 0 & 5.917 & 1.19 & 0.982 & 0 & 3.55 \\
\hline \multirow{2}{*}{$\mathrm{C}$} & $\mathrm{C}_{\mathrm{AD}}$ & 2.853 & 3.048 & 0 & 14 & 2.853 & 2.108 & 0 & 8 \\
\hline & $\mathrm{C}_{\mathrm{RD}}$ & 1.688 & 1.804 & 0 & 8.284 & 1.688 & 1.247 & 0 & 4.734 \\
\hline \multirow{2}{*}{$\mathrm{D}$} & $\mathrm{C}_{\mathrm{AD}}$ & 1.606 & 2.146 & 0 & 15 & 1.606 & 1.527 & 0 & 7 \\
\hline & $\mathrm{C}_{\mathrm{RD}}$ & 0.95 & 1.27 & 0 & 8.876 & 0.95 & 0.904 & 0 & 4.142 \\
\hline \multirow{2}{*}{$\mathrm{E}$} & $\mathrm{C}_{\mathrm{AD}}$ & 2.347 & 3.211 & 0 & 24 & 2.347 & 2.004 & 0 & 9 \\
\hline & $\mathrm{C}_{\mathrm{RD}}$ & 1.389 & 1.9 & 0 & 14.201 & 1.389 & 1.186 & 0 & 5.325 \\
\hline \multirow{2}{*}{$\mathrm{F}$} & $\mathrm{C}_{\mathrm{AD}}$ & 2.488 & 2.59 & 0 & 15 & 2.488 & 1.974 & 0 & 8 \\
\hline & $\mathrm{C}_{\mathrm{RD}}$ & 1.472 & 1.533 & 0 & 8.876 & 1.472 & 1.168 & 0 & 4.734 \\
\hline \multirow{2}{*}{ G } & $\mathrm{C}_{\mathrm{AD}}$ & 2.347 & 2.407 & 0 & 14 & 2.347 & 1.819 & 0 & 7 \\
\hline & $\mathrm{C}_{\mathrm{RD}}$ & 1.389 & 1.424 & 0 & 8.284 & 1.389 & 1.076 & 0 & 4.142 \\
\hline \multirow{2}{*}{$\mathrm{H}$} & $\mathrm{C}_{\mathrm{AD}}$ & 1.541 & 1.719 & 0 & 9 & 1.541 & 1.511 & 0 & 7 \\
\hline & $\mathrm{C}_{\mathrm{RD}}$ & 0.912 & 1.017 & 0 & 5.325 & 0.912 & 0.894 & 0 & 4.142 \\
\hline
\end{tabular}

Note. CAD is an absolute value, $\mathrm{CRD}$ is a relative value, and relative value is a percentage.

Among the three discussion networks, there are athletes who do not participate in any discussion network. Similarly, from the view of maximum value, the out-degree is generally greater than the in-degree, indicating that professional athletes actively take part in discussions more than passively. Among them, there are more discussions on income and professional sports team management, but less on marriage, which has something to do with the younger age of professional athletes and the sensitive topics of marriage involved.

From the perspective of the characteristics of degree centrality, several adjustment ideas are proposed for the practice of training guidance and life guidance in the future: first, according to the athlete's strong initiative, the coaching staff can set up a special person to communicate with the athletes for help information and provide as many assistance items as possible according to the athlete's type of help. Secondly, due to the strong initiative of the athletes to participate in the discussion, the coaching staff needs to conduct psychological counseling and dredging frequently. Finally, the coaching staff should pay attention to some athletes who tend to self-isolate and guide them to establish social support and discussion links with other teammates.

4.1.2. Betweenness Centrality. Table 2 provides the betweenness centrality of the social support network and social discussion network of professional athletes. It can be seen that, in the five social support networks, the mean value of the actual support network is obviously higher than that of other networks. It can be understood that more athletes play the role of bridge in the actual support network, followed by society intercourse, emotional support, employment support, and achievement support. In three society discussion networks, we can see that the minimum value is zero and we can assume that, in every topic, there are athletes who cannot fit in other two discussion relationships; that is, they do not have the ability to control the discussion relationship. Athletic groups have different centrality in social support and social discussion which means that they have different "power" structure in the group. Whether social support or social discussion, there are a small number of athletes in isolation. They do not have any "power." Overall speaking, the centrality of actual support is high, while that of emotional support is poor. For social discussion, the more common the topic is, the higher the centrality of the corresponding network is. On the contrary, the more private the topic is, the lower the centrality of the corresponding network is $[33,34]$.

According to the analysis of the centrality characteristics, the coaching staff should encourage athletes to increase the necessary contact between teammates, especially to increase emotional and spiritual communication, which will help improve the network "power" structure. At the same time, we must focus on the more important nodes in the "bridge relationship," which will have a multiplier effect on team management.

4.1.3. Closeness Centrality. Table 3 provides the closeness centrality of the society support network and society discussion network of professional athletes. The closeness centrality requires that the graph must be a connected graph; that is, any two points in the network can be linked together through a certain path. According to the data, we can find that the professional athlete network is relatively sparse and there are isolated points and disconnected subnetworks $[33,34]$.

According to the characteristics of the sparse network, the information circulation space of the athlete group is worthy of further exploration. It is recommended to guide the players to strengthen mutual learning and cooperation among different objects in the process of training and life guidance. 
TABLE 2: Social network betweenness centrality of professional athletes.

\begin{tabular}{|c|c|c|c|c|c|c|}
\hline & & Mean value & Standard deviation & Total & Minimum value & Maximum value \\
\hline \multirow{2}{*}{ A } & $\mathrm{C}_{\mathrm{AD}}$ & 249.69 & 444.21 & 36704 & 0 & 2062.55 \\
\hline & $\mathrm{C}_{\mathrm{RD}}$ & 1.18 & 2.10 & 173.38 & 0 & 9.74 \\
\hline \multirow{2}{*}{ B } & $\mathrm{C}_{\mathrm{AD}}$ & 55.42 & 110.33 & 8147 & 0 & 610.83 \\
\hline & $\mathrm{C}_{\mathrm{RD}}$ & 0.26 & 0.52 & 38.48 & 0 & 2.89 \\
\hline \multirow{2}{*}{$\mathrm{C}$} & $\mathrm{C}_{\mathrm{AD}}$ & 125.62 & 276.75 & 18466 & 0 & 1954.97 \\
\hline & $\mathrm{C}_{\mathrm{RD}}$ & 0.59 & 1.31 & 87.23 & 0 & 9.24 \\
\hline \multirow{2}{*}{$\mathrm{D}$} & $\mathrm{C}_{\mathrm{AD}}$ & 18.79 & 40.76 & 2762 & 0 & 181.00 \\
\hline & $\mathrm{C}_{\mathrm{RD}}$ & 0.09 & 0.19 & 13.05 & 0 & 0.86 \\
\hline \multirow{2}{*}{$\mathrm{E}$} & $\mathrm{C}_{\mathrm{AD}}$ & 16.73 & 39.81 & 2459 & 0 & 297.50 \\
\hline & $\mathrm{C}_{\mathrm{RD}}$ & 0.08 & 0.19 & 11.62 & 0 & 1.41 \\
\hline \multirow{2}{*}{$\mathrm{F}$} & $\mathrm{C}_{\mathrm{AD}}$ & 27.57 & 51.61 & 4052 & 0 & 408.05 \\
\hline & $\mathrm{C}_{\mathrm{RD}}$ & 0.13 & 0.24 & 19.14 & 0 & 1.93 \\
\hline \multirow{2}{*}{$\mathrm{G}$} & $\mathrm{C}_{\mathrm{AD}}$ & 20.25 & 38.54 & 2976 & 0 & 289.17 \\
\hline & $\mathrm{C}_{\mathrm{RD}}$ & 0.10 & 0.18 & 14.06 & 0 & 1.37 \\
\hline \multirow{2}{*}{$\mathrm{H}$} & $\mathrm{C}_{\mathrm{AD}}$ & 13.71 & 42.36 & 2016 & 0 & 306.83 \\
\hline & $\mathrm{C}_{\mathrm{RD}}$ & 0.07 & 0.20 & 9.52 & 0 & 1.45 \\
\hline
\end{tabular}

Note. $C_{A D}$ is an absolute value, $C_{R D}$ is a relative value, and relative value is a percentage.

TABLE 3: The closeness centrality of the society of professional athletes.

\begin{tabular}{|c|c|c|c|c|c|c|c|c|}
\hline & \multicolumn{4}{|c|}{ Out-degree } & \multicolumn{4}{|c|}{ In-degree } \\
\hline & $\begin{array}{l}\text { Mean } \\
\text { value }\end{array}$ & $\begin{array}{l}\text { Standard } \\
\text { deviation }\end{array}$ & $\begin{array}{l}\text { Minimum } \\
\text { value }\end{array}$ & $\begin{array}{l}\text { Maximum } \\
\text { value }\end{array}$ & $\begin{array}{l}\text { Mean } \\
\text { value }\end{array}$ & $\begin{array}{l}\text { Standard } \\
\text { deviation }\end{array}$ & $\begin{array}{l}\text { Minimum } \\
\text { value }\end{array}$ & $\begin{array}{l}\text { Maximum } \\
\text { value }\end{array}$ \\
\hline \multirow{2}{*}{ A } & 13893.24 & 5115.757 & 8082 & 21462 & 13893.24 & 5305.243 & 1397 & 21462 \\
\hline & 1.214 & 0.444 & 0.68 & 1.806 & 1.534 & 1.838 & 0.68 & 10.451 \\
\hline \multirow{2}{*}{ B } & 18842.74 & 2227.149 & 14785 & 21462 & 18842.74 & 2613.77 & 13037 & 21462 \\
\hline & 0.786 & 0.095 & 0.68 & 0.987 & 0.793 & 0.129 & 0.68 & 1.12 \\
\hline \multirow{2}{*}{$\mathrm{C}$} & 16592.83 & 2736.615 & 12063 & 21462 & 16592.83 & 5873.589 & 3684 & 21462 \\
\hline & 0.904 & 0.147 & 0.68 & 1.21 & 1.164 & 0.878 & 0.68 & 3.963 \\
\hline \multirow{2}{*}{$\mathrm{D}$} & 20197.58 & 1458.593 & 16003 & 21462 & 20197.58 & 1453.342 & 16701 & 21462 \\
\hline & 0.727 & 0.058 & 0.68 & 0.912 & 0.727 & 0.056 & 0.68 & 0.874 \\
\hline \multirow{2}{*}{$\mathrm{E}$} & 20107.12 & 1148.178 & 17448 & 21462 & 20107.12 & 1303.288 & 17545 & 21462 \\
\hline & 0.729 & 0.043 & 0.68 & 0.837 & 0.729 & 0.05 & 0.68 & 0.832 \\
\hline \multirow{2}{*}{$\mathrm{F}$} & 19534.95 & 1688.046 & 14983 & 21462 & 19534.95 & 1398.181 & 17469 & 21462 \\
\hline & 0.754 & 0.071 & 0.68 & 0.974 & 0.751 & 0.054 & 0.68 & 0.836 \\
\hline \multirow{2}{*}{ G } & 19935.84 & 1286.519 & 16737 & 21462 & 19935.84 & 1056.923 & 18150 & 21462 \\
\hline & 0.736 & 0.05 & 0.68 & 0.872 & 0.734 & 0.039 & 0.68 & 0.804 \\
\hline \multirow{2}{*}{$\mathrm{H}$} & 20457.69 & 1192.434 & 17448 & 21462 & 20457.69 & 1220.173 & 17456 & 21462 \\
\hline & 0.716 & 0.045 & 0.68 & 0.837 & 0.716 & 0.046 & 0.68 & 0.836 \\
\hline
\end{tabular}

4.2. Mesostructure Analysis. According to the view of Newman, the larger the $Q$ value is, the better the detection effect of community structure and the clearer the community structure are. Generally, $Q$ value is between 0.3 and 0.7. However, the modular $Q$ value is problematic and the three networks in Figure 2 are used as an example to illustrate.

Network 1 and network 2 are very similar with a clear community structure and the same community; that is, each subgroup has five interconnected nodes. The only difference is that network 1 has two communities, while network 2 has four communities. Their $Q$ values are, respectively, 0.4036 and 0.6591 . For network 3 , the same as network 1 , there are two communities, but the number of nodes in the community is different, one is 5, the other is 10 , and the $Q$ value is 0.2688 . The above example is quite different from the view of
Newman. Therefore, the $Q$ value of the community structure can be affected by the network structure [34].

Table 4 is the optimal modularity index of social network community structure detection for athletes. It can be seen that the modularity value of all other networks except social communication support and employment support network is greater than 0.8 , indicating that community structure widely exists in professional athlete network.

The modular value of social discussion network is generally greater than that of the social support network, which shows that once personal privacy issues are involved, athletes are often only discussing with people in small communities and are not willing to communicate with other community members [35]. In a word, the differences in personality, growth background, education level, and other aspects will naturally lead to individual differences of 


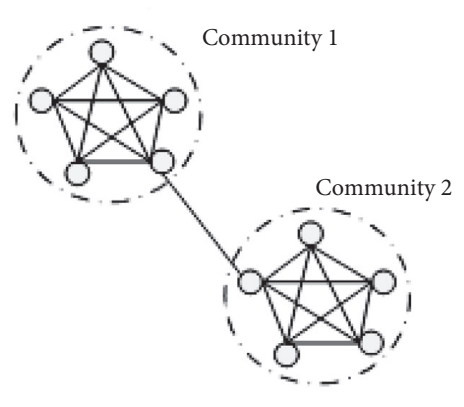

(a)

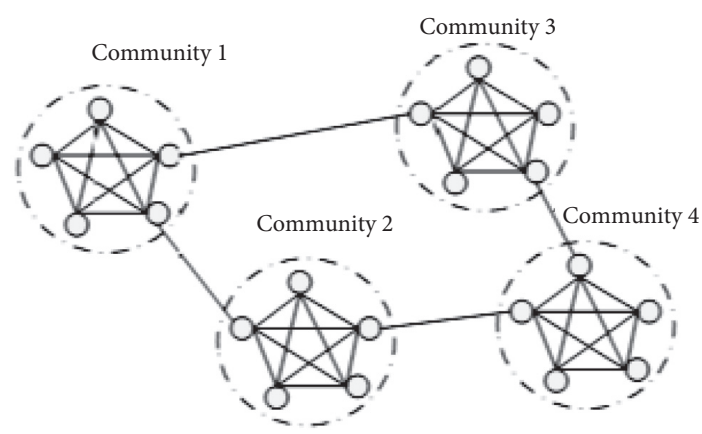

(b)

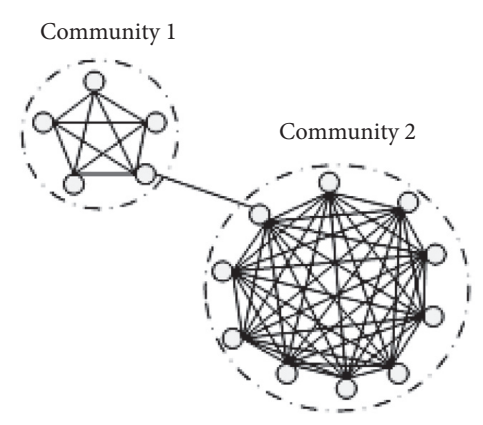

(c)

Figure 2: Schematic diagram of community structure. (a) Network1. (b) Network2. (c) Network3.

TABLE 4: Modular indicators of professional athletes.

\begin{tabular}{ccccccccr}
\hline & A & B & C & D & E & F & G & H \\
\hline Modulari & 0.8011 & 0.8392 & 0.7899 & 0.7991 & 0.8147 & 0.8406 & 0.8577 & 0.8367 \\
\hline
\end{tabular}

athletes, which determines that the social network structure of the athletes group cannot be exactly the same [36].

Based on the above analysis results, it is recommended to strengthen the improvement of athletes' individual attributes, such as the improvement of education level and the psychological guidance of lonely personality, which will contribute to the beingness of the network structure of the entire athlete team.

\subsection{Macrostructural Analysis}

4.3.1. Degree Centralization. Table 5 provides the degree centralization of the professional athletes' social support network and social discussion network. The in-degree centralization is a measure of the difference between the number of other individuals in the network and the individual as a whole. When the difference is greater in degree, it shows that the difference in the popularity of individual Internet users is greater. The out-degree centralization measures the size of the difference in the number of individuals in contact with other individuals in the network as a whole. When the difference is greater in degree, it shows that the difference between the network members' ability to contact others is greater and the centralization is greater. We can see that the centralization of achievement support networks and actual support networks is relatively greater, in the top five social support networks. It indicates that these two social networks are relatively concentrated, then followed by employment support, society intercourse support, and emotional support. Among the three social discussion networks, the centralization is in sequence income discussion network, profession discussion network, and marriage discussion network [36].

Based on the above analysis, it is recommended to strengthen the support of athletes' social support appeals as a whole, encourage more communication between players, and further reduce the differences in passive communication.

4.3.2. Betweenness Centralization. Table 6 provides the betweenness centralization of professional athletes' social support network and social discussion network, which is a measure of the difference in the number of paths between each individual in the overall network. The betweenness centralization is to measure the size of the difference between the individual in the overall network as the communication bridge between the other two individuals. When the difference is greater in degree, it shows that the minority have the greater ability to control the individual communication in the network [37]. It can be seen from the table that, in the actual support and society intercourse support network, the betweenness centralization is the greater, indicating that some of the athletes have greater individual control capabilities, while there is not much difference in the discussion network [38].

According to the analysis of the betweenness centralization, the research believes that the management of actual support relationships and social interaction support relationships can focus on the important bridge node sets, because they will affect some of the surrounding nodes. For other relationships, such as employment support relationships, this is not necessary.

4.3.3. Embeddability. The method of embeddability analysis is to check the correlation of the two relationship matrices. The specific method is the QAP method, that is, the Quadratic Assignment Procedure. This method based on resampling has been widely used in social networks. In the specific calculation, QAP compares the similarity of each element in the two square matrices, gives the correlation 
TABLE 5: Degree centralization of professional athletes' social network.

\begin{tabular}{lcccccccc}
\hline & $\mathrm{A}$ & $\mathrm{B}$ & $\mathrm{C}$ & $\mathrm{D}$ & $\mathrm{E}$ & $\mathrm{F}$ & $\mathrm{G}$ & $\mathrm{H}$ \\
\hline Out & $13.78 \%$ & $5.29 \%$ & $7.38 \%$ & $9.06 \%$ & $14.68 \%$ & $8.36 \%$ & $7.78 \%$ & $4.98 \%$ \\
In & $4.13 \%$ & $2.53 \%$ & $3.24 \%$ & $3.55 \%$ & $4.34 \%$ & $3.53 \%$ & $2.96 \%$ & $3.60 \%$ \\
\hline
\end{tabular}

TABLE 6: Betweenness centralization of professional athletes' social network.

\begin{tabular}{ccccccccc}
\hline & $\mathrm{A}$ & $\mathrm{B}$ & $\mathrm{C}$ & $\mathrm{D}$ & $\mathrm{E}$ & $\mathrm{F}$ & $\mathrm{G}$ & $\mathrm{H}$ \\
\hline Betweenness centralization & $8.62 \%$ & $2.64 \%$ & $8.70 \%$ & $0.77 \%$ & $1.34 \%$ & $1.81 \%$ & $1.28 \%$ & $1.39 \%$ \\
\hline
\end{tabular}

coefficient between the two matrices and performs a nonparametric test on the coefficient, and calculates that the correlation coefficient after random replacement is greater than the probability of the actual correlation coefficient. The principle is that all the numerical values in each matrix are treated as a long vector, and each vector contains $n(n-1)$ numbers (diagonal numbers are not considered) and then calculates the correlation coefficient. If the probability is less than 0.05 , it means that there is a correlation between the two matrices. The calculation of the correlation coefficient is done using the software UCINET [34, 39].

It can be seen from Table 7 that there is a significant correlation between professional athletes' social networks, indicating that there are overlapping members in eight different types of networks, and there is also a strong correlation between athletes' society support network and society discussion network. It shows that a considerable part of the support network members is also members of its discussion network.

According to the analysis of embeddability, the research believes that, in order to reduce research and management costs, the structure of the social discussion network can be inferred through the athlete's social support network in the case of nonstrict requirements.

4.3.4. Density Structure Analysis. Presentation of the overall network structure features is mainly density, and the density in a directed network is $d=\left(\sum_{i=1}^{n} \sum_{j=1}^{n} X_{i j} / n(n-1)\right), n$ represents the size of the network.

It can be seen from Table 8 that the relationship density of the social support of professional athletes is different. Among the five social networks, the actual support network and the social interaction support network are relatively dense, followed by achievement support network, emotional support network, and employment support network. For the three discussion networks, the discussion density on income topics is higher, followed by professional discussions, and the discussion density on marriage is lower. In general, no matter the social support network or discussion network, professional athletes are lacking emotional communication [40].

According to the above analysis, we should focus on the actual support relationship and social interaction support relationship between players in the work, because athletes use these two relationships more, and other relationships take second place.
TABLE 7: Social network relevance of professional athletes.

\begin{tabular}{lcccccccc}
\hline & AA & BB & CC & DD & EE & FF & GG & HH \\
\hline AA & 1 & 0.641 & 0.670 & 0.515 & 0.557 & 0.622 & 0.633 & 0.568 \\
BB & 0.641 & 1 & 0.667 & 0.543 & 0.591 & 0.638 & 0.646 & 0.670 \\
CC & 0.670 & 0.667 & 1 & 0.551 & 0.559 & 0.635 & 0.622 & 0.591 \\
DD & 0.515 & 0.543 & 0.551 & 1 & 0.520 & 0.507 & 0.511 & 0.517 \\
EE & 0.557 & 0.591 & 0.559 & 0.520 & 1 & 0.588 & 0.574 & 0.563 \\
FF & 0.622 & 0.638 & 0.635 & 0.507 & 0.588 & 1 & 0.750 & 0.647 \\
GG & 0.633 & 0.646 & 0.622 & 0.511 & 0.574 & 0.750 & 1 & 0.641 \\
HH & 0.568 & 0.670 & 0.591 & 0.517 & 0.563 & 0.647 & 0.641 & 1 \\
\hline
\end{tabular}

Note. The number of random transformations in the calculation process is 5000, and all $p$ values are 0.000 . The output Prop $\geq 0$ (these randomly calculated correlation coefficients are greater than or equal to the actual correlation coefficient) is 0.000 , and Prop $\leq 0$, the probability is 1.000 .

4.3.5. Theoretical Analysis of Structural Characteristics of Small World. The small-world phenomenon reveals the most effective way of information transfer between realworld actors. At present, there is not any precise definition of the small-world network. It is generally believed that if the average distance $L$ between two nodes in the network increases logarithmically with the number of network nodes $n$, $L \propto \ln n$, the network is called a small-world network $[41,42]$.

The clustering coefficient and the average path length are two important characteristic indicators for investigating small-world networks. The clustering coefficient reflects the degree of aggregation of the network nodes and refers to the possibility that two other nodes connected to the same node are also connected. The larger the clustering coefficient, the more stable the relationship between network members.

The average path length refers to the average number of steps, which an individual in the overall network gets to another individual.

It can be seen from Tables 9 and 10 that the society discussion network of athletes has obvious small-world characteristics, while the society support network has high clustering, but the average path length is long. This characteristic shows that income discussion, professional discussion, and marriage discussion spread quickly in the social network because of the short path and the small spread range of the athletes' social network, with a shorter path, but a smaller range of relationship transmission. In contrast, social support relationships have a longer propagation path and wider relationships. It explains that the most private discussion relationship has the shortest propagation path, so 
TABLE 8: Social network density of professional athletes.

\begin{tabular}{cccccccrr}
\hline & A & B & C & D & E & F & G & H \\
\hline Density & 0.0275 & 0.0159 & 0.0226 & 0.0127 & 0.0186 & 0.0197 & 0.0186 & 0.0122 \\
\hline
\end{tabular}

TABLe 9: Average clustering coefficient of professional athletes' social network.

\begin{tabular}{lcccccccc}
\hline & A & B & C & D & E & F & G & H \\
\hline Local clustering & 0.405 & 0.352 & 0.382 & 0.370 & 0.427 & 0.423 & 0.423 & 0.387 \\
Transitive clustering & 0.298 & 0.320 & 0.331 & 0.221 & 0.313 & 0.375 & 0.411 & 0.347 \\
\hline
\end{tabular}

TABLE 10: Average path length of professional athletes' social network.

\begin{tabular}{ccccccccc}
\hline & A & B & C & D & E & F & G & H \\
\hline Path length & 5.663 & 4.025 & 4.672 & 3.138 & 2.781 & 3.059 & 2.911 & 2.967 \\
\hline
\end{tabular}

the propagation speed may be faster. Among the five social support networks, the average path of achievement support is the shortest, indicating that the support for professional technology among athletes is better, and everyone communicates more. This is consistent with the shorter average path of the professional discussion network in the discussion network.

The small-world characteristics in the athlete network can be effectively used in athlete management. In the "small world," it is conducive to the rapid establishment of contacts and the effective dissemination of management information. It is also conducive to the role of group wisdom.

\section{Conclusion}

This study uses complex network analysis methods to analyze the micro-, meso-, and macrostructural characteristics of the athlete's overall social network (a total of eight overall networks including society support network and society discussion network). Using complex society network analysis methods, this study analyzes the complex overall network characteristics of professional athletes' social network including three aspects: the first is scale-free feature and connection tendency analysis at microlevel; second, it improves the community structure detection algorithm based on complex network analysis and analyzes the community structure of athletes' social network; third, it analyzes the small-world characteristics of athletes' social network. Specific analysis methods include structural hole analysis, cohesive subgroup analysis, core-periphery structure analysis, small-world feature analysis, community structure analysis, and scale-free feature analysis.

The study found the following:

(1) The microstructure of social networks of professional athletes shows that no matter whether it is a society support network or a society discussion network, some athletes have no contact with other team members. They have no "power" in the group and it is difficult to obtain network resources.
Because access to resources is more urgent than the exchange of ideas between athletes, the centrality of athletes' society support networks is higher than that of society discussion networks as a whole. For the social support network, the actual support and society support are more central than emotional support, because the return of the energy invested in the former is relatively greater, and insufficient emotional support is the main problem of the athletic team. In terms of collective discussions, income and professionalism are the main topics of discussion. Compared with the topic of marriage, the topic of marriage is relatively few discussions, which are related to the age of athletes and the applicable regulations of sports teams. Some athletes act as "information bridge" in group communication and have a dominant role in the acquisition of network resources or the spread of ideas.

(2) The mesostructure of professional athletes' social network shows that the structure of athletes' small groups is sparse, and social discussions mainly take place among small groups with communal support relationships. There are more factions in the social support network than in the communal discussion network; correspondingly, there are more cliques overlapping members in the social support network. Overlapping cliques become more active than other members. No matter what social support or social discussion, some athletes are relatively isolated. They neither communicate with other athletes in the same structural position nor actively communicate with other groups. They only accept passively and are in a passively dominant position. Society discussion networks are easier to form small groups than society support networks.

(3) The macrostructure of professional athletes' society networks shows that there is embeddedness, that is, the relevance, between society support networks, between society discussion networks, and between 
society support networks and society discussion networks. On the whole, athletes are more practicing and active when seeking social support or social discussion and more passive when receiving social support or social discussion. At the same time, the social network of professional athletes has the characteristics of a small world, and society discussion network is more obvious than the society support network. The characteristics of the small world reflect the rich local connection and few random long-distance connections in the society network of athletes, indicating that there are short paths in society relations. Particularly for the societal discussion network, this short path is conducive to the rapid establishment of society support relationships between individual athletes.

(4) The research on the complex society network of professional athletes shows that professional athletes' society intercourse has self-organizing features. A few athletes are in an advantageous position in interpersonal communication and have more society relationships. In the process of communication, diverse small groups will be formed. Most of them are small-scale groups, and the small-world phenomenon still exists.

\section{Data Availability}

The original data used in this study are the questionnaire data obtained from the survey. The original data used to support the findings of this study are available from the corresponding author upon request.

\section{Conflicts of Interest}

The authors declare that they have no conflicts of interest.

\section{Acknowledgments}

This work was supported in part by the 2020 Science and Technology Project in Yulin National High Tech Industrial Development Zone under Grant CXY-2020-17.

\section{References}

[1] Q. Li, B. Liu, and Y. Zhao, "Construction of statistical metadata in the big data environment," Journal of Statistics and Information, vol. 35, no. 3, pp. 14-20, 2020.

[2] R. Zhang, L. Liu, X. Tang, and B. Zhang, "Research on commodity retail price index prediction based on web search data in the context of big data," Journal of Statistics and Information, vol. 35, no. 11, pp. 49-56, 2020.

[3] Z. Pang and M. Zeng, "Has internet use affected youth subjective well-being? An analysis from CGSS 2010-2015 data," Journal of Xi'an University of Finance and Economics, vol. 33, no. 3, pp. 71-77, 2020.

[4] J. Scott and P. J. Carrington, The SAGE Handbook of Social Network Analysis, SAGE, Thousand Oaks, CA, USA, 2011.

[5] A. Biswas and B. Biswas, "Investigating community structure in perspective of ego network," Expert Systems with Applications, vol. 42, no. 20, pp. 6913-6934, 2015.
[6] J. O. Kereri and C. M. Harper, "Social networks and construction teams: literature review," Journal of Construction Engineering and Management, vol. 145, no. 4, Article ID 03119001, 2019.

[7] H. Yang, Z. Hao, and K. Wang, "Social network and HIV transmission China AIDS,” STD, vol. 1, pp. 47-50, 2003.

[8] J. Liu, Introduction to Social Network Analysis, China Social Science Publishing, Beijing, China, 2004.

[9] R. Leonard, D. Horsfall, and K. Noonan, "Identifying changes in the support networks of end-of-life carers using social network analysis," BMJ Supportive \& Palliative Care, vol. 5, no. 2, pp. 153-159, 2015.

[10] T. W. Valente and S. R. Pitts, "An appraisal of social network theory and analysis as applied to public health: challenges and opportunities," Annual Review of Public Health, vol. 38, no. 1, pp. 103-118, 2017.

[11] D. Hussein, S. Park, S. N. Han, and N. Crespi, "Dynamic social structure of things: a contextual approach in CPSS," IEEE Internet Computing, vol. 19, no. 3, pp. 12-20, 2015.

[12] B. S. Hanson, B. Liedberg, and B. Owall, "Social network, social support and dental status in elderly Swedish men," Community Dentistry \& Oral Epidemiology, vol. 22, no. 5, pp. 331-337, 2015.

[13] F. Xiong, X. Wang, S. Pan, H. Yang, H. Wang, and C. Zhang, "Social recommendation with evolutionary opinion dynamics," IEEE Transactions on Systems, Man, and Cybernetics: Systems, vol. 50, no. 10, pp. 3804-3816, 2020.

[14] F. W. Frey, E. Abrutyn, and D. S. Metzger, "Focal networks and HIV risk among African-American male intravenous drug users/needle RH," Social Networks, Drug Abuse, and HIV Transmission, S. G. Genser and R. T. Trotter, Eds., Springer, Berlin, Germany, 1995.

[15] G. C. Loury, "A dynamic theory of racial income differences," in Women, Minorities, and Employment Discrimination, P. A. Wallace and A. M. La Mond, Eds., D.C. Heath and Company, Lexington, MA, USA, 1977.

[16] D. Mehrle, A. Strosser, and A. Harkin, "Walk-modularity and community structure in networks," Network Science, vol. 3, no. 3, pp. 348-360, 2015.

[17] M. E. J. Newman and M. Girvan, "Finding and evaluating community structure in networks," Physical Review E, vol. 69, Article ID 026113, 2004.

[18] L. Nan, Social Capital-Theory on Social Structure and Action, Shanghai People's Publishing House, Shanghai, China, 2005.

[19] J. Luo, Lecture Notes on Social Network Analysis, Social Sciences Literature Press, Beijing, China, 2005.

[20] B. Bollobás, Random Graphs, Academic Press Inc., London, UK, 1985.

[21] A.-L. Barabási, R. Albert, and R. Albert, "Emergence of scaling in random networks," Science, vol. 286, pp. 509-512, 1999.

[22] N. Gupta, V. Ho, J. M. Pollack, and L. Lai, "A multilevel perspective of interpersonal trust: individual, dyadic, and cross-level predictors of performance," Journal of Organizational Behavior, vol. 37, no. 8, pp. 1271-1292, 2016.

[23] M. A. J. van Duijn, T. A. B. Snijders, and B. J. H. Zijlstra, "p2: a random effects model with covariates for directed graphs," Statistica Neerlandica, vol. 58, no. 2, pp. 234-254, 2004.

[24] C. J. Mitchell, "The concept and use of social networks," in Social Network in Urban Situations, C. J. Mitchell, Ed., Manchester University Press, Manchester, UK, 1969.

[25] P. Carrington, "Network as personal communities," in Social Structure: A Network Approach, B. Wellman, Ed., Cambridge University Press, Cambridge, UK, 1988. 
[26] Welman and W. Zhang, "Network analysis: from method and metaphor to theory and essence," Foreign Sociology, vol. 17, no. 2, p. 8, 1994.

[27] H. Qian and X. Zhang, "Theoretical analysis of Chinese athletes' social network and social support," Journal of Xi'an Institute of Physical Education, vol. 29, no. 1, pp. 1-5, 2012.

[28] N. R. Taylor, "Small world network strategies for studying protein structures and binding," Computational \& Structural Biotechnology Journal, vol. 5, no. 6, pp. 1-7, 2013.

[29] A. Roxin, H. Riecke, and S. A. Solla, "Self-sustained activity in a small-world network of excitable neurons," Physical Review Letters, vol. 92, no. 19, Article ID 198101, 2004.

[30] Y. B. Xie, T. Zhou, and B. H. Wang, "Scale-free networks without growth," Physica A: Statal Mechanics and Its Applications, vol. 387, no. 7, pp. 1683-1688, 2017.

[31] S. C. Ponten, F. Bartolomei, and C. J. Stam, "Small-world networks and epilepsy: graph theoretical analysis of intracerebrally recorded mesial temporal lobe seizures," Clinical Neurophysiology, vol. 118, no. 4, pp. 918-927, 2007.

[32] Z. He, "A review of foreign social support network research," Foreign Social Sciences, vol. 24, no. 1, pp. 76-81, 2001.

[33] J. Liu, Fa Village Social Support Network: A Perspective of Holistic Research, Social Science Literature Press, Beijing, China, 2006.

[34] Y. Bian, "The source and function of urban residents' social capital: network views and survey findings," Chinese Social Sciences, vol. 3, pp. 136-146, 2004.

[35] Y. Hu, F. Xiong, S. Pan, X. Xiong, L. Wang, and H. Chen, "Bayesian personalized ranking based on multiple-layer neighborhoods," Information Sciences, vol. 542, pp. 156-176, 2021.

[36] H. Qian and X. Zhang, "The impact of personal characteristics of professional athletes on the structure of social support network in my country," Journal of Shanghai Institute of Physical Education, vol. 38, no. 6, pp. 59-64, 2014.

[37] F. Xiong, W. Shen, H. Chen, S. Pan, X. Wang, and Z. Yan, "Exploiting implicit influence from information propagation for social recommendation," IEEE Transactions on Cybernetics, vol. 50, no. 10, pp. 4186-4199, 2020.

[38] W. Wang, "Social capital and personal capital of Chinese urban residents," Sociological Research, vol. 21, no. 3, pp. 151-166, 2006.

[39] M. Tortoriello, "The social underpinnings of absorptive capacity: the moderating effects of structural holes on innovation generation based on external knowledge," Strategic Management Journal, vol. 36, no. 4, pp. 586-597, 2015.

[40] H. Qian and X. Zhang, "Research on the structural characteristics of individual center network of Chinese professional athletes," Journal of Xi'an Institute of Physical Education, vol. 31, no. 1, pp. 1-6, 2014.

[41] L. I. Bo, W. Lei, and School of P.E., "Feasibility analysis of passing performance in football match by social network analysis," Journal of Beijing Sport University, vol. 40, no. 8, pp. 112-119, 2017.

[42] Z. Jianyu, X. Xi, and S. Yi, "A simulation research on small world effect in knowledge flow's network evolution," Management Review, vol. 27, no. 5, pp. 70-81, 2015. 